\title{
Study on the pore surface fractal dimension and surface acid-base properties of natural particles around Guanting reservoir
}

\author{
Yili Wang ${ }^{\mathrm{a}, *}$, Baiyu Du ${ }^{\mathrm{a}}$, Xiaomin Dou ${ }^{\mathrm{a}}$, Jie Liu ${ }^{\mathrm{a}}$, \\ Baoyou Shi ${ }^{b}$, Dongsheng Wang ${ }^{b}$, Hongxiao Tang ${ }^{b}$ \\ ${ }^{a}$ Environmental Science, College of Nature Resource and Environment, The Key Laboratory for Silviculture and \\ Conservation of Ministry of Education and Beijing, Beijing Forestry University, Beijing 100083, China \\ b State Key Laboratory of Environmental Aquatic Chemistry, Research Center for Eco-Environmental Sciences, \\ Chinese Academy of Sciences, Beijing 100085, China
}

Received 4 December 2006; received in revised form 18 April 2007; accepted 24 April 2007 Available online 29 April 2007

\begin{abstract}
Nitrogen absorption-desorption isotherms were obtained on different natural particles around Guanting reservoir, and their data points were used to analyze the pore structure and fractal properties of the obtained solids. Other microstructure parameters of these particles are the following: $9.5669-4.5605 \mathrm{~m}^{2} \mathrm{~g}^{-1}$ of BET specific surface area, $0.01784-0.06656 \mathrm{~cm}^{3} \mathrm{~g}^{-1}$ of BJH cumulative absorbed volume and 7.20-7.74 $\mathrm{nm}$ of BJH desorption average pore diameter. The peak values of pore size distribution (PSD) curves were found at near $3.74 \mathrm{~nm}$ for samples 2, 3 and 4 , and near $3.25 \mathrm{~nm}$ for sample 1, and near $5.17 \mathrm{~nm}$ for sample 5. The average pore diameter was larger than that corresponding to the peak value of pore size distribution (PSD). The micropore areas are very small in these particles, but their micropore volume of them can occupy over $15 \%$ of total pore volume.

The self-similar and rough surface was observed on these particles, and the pore surface fractal dimensions $D_{\text {s }}$ of them were between 2.69 and 2.80, calculated by fractal FHH equation with the data of the adsorption branch of the isotherm, are a little difference from ones with the isotherm data of desorption branch, and also their corresponding fractal scales are different. It may be attributed to the different $p / p_{0}$ range for $D_{\mathrm{s}}$ values calculation and pore structure property. Otherwise, the computing $D_{\mathrm{s}}$ values by thermodynamic model do not give meaningful indication for particle surface irregularity.

There are about 1-2 specific surface sites $\left(D_{\mathrm{OH}}\right)$ in each square nanometers on these particles surface, and at most pH range, the average number of protons reacted per surface site $(Z)$ have negative values, and only when $\mathrm{pH}$ values are lower than about $4, Z$ can have positive values. Potentiometric titration experiment and two surface complexation model simulation results indicate that CCM simulation results can better interpret the experiment data points than DLM at $0.005 \mathrm{~mol} \mathrm{~L}^{-1}$ ion strength. Based on the CCM, the protonation and deprotonation reactions model can successfully depicted the acid-base behavior of natural particles surface, and the surface intrinsic acidic constants and the total concentration of surface sites for these natural particles, could be obtained.
\end{abstract}

(C) 2007 Elsevier B.V. All rights reserved.

Keywords: Natural particles; Pore surface fractal dimension; Fractal scale; Potentiometric titration; Acid-base properties

\section{Introduction}

Sediment and soil particles are important parts of particles in natural water environment, and their existence can affect the speciation distribution, transportation and transformation of many

\footnotetext{
* Corresponding author. Tel.: +86 10 62337917; fax: +86 1062341948

E-mail addresses: wangyilimail@126.com,wangyilinet@sina.com (Y. Wang).
}

pollutants, such as heavy metals, inorganic nutrients and toxic organic matters. These particles can act as micro-reactors since a large number of physicochemical and biological reactions can happen on the solid-liquid micro-interfaces, and determine their fates at last. Then the combined particles with the reactants or products in their surface can be formed and as the secondary pollution resource with potential risk for aquatic environment [1-4].

The surface and pores morphology of natural particles can be a key factor for above processes. It was generally assumed that 


\section{Nomenclature}

$D_{\mathrm{OH}} \quad$ the specific surface sites of the particles

$D_{\mathrm{s}} \quad$ surface fractal dimension

$E \quad$ the potential of the glass electrode

$F \quad$ the Faraday constant

$G \quad$ Gran function

$H_{\mathrm{R}}$ the amount of protons consumed by all surface sites

$H_{\mathrm{S}} \quad$ the total concentration of surface sites

$K_{a 1}, K_{a 2}$ equilibrium constants

$K_{a 1}^{\text {int }}, K_{a 2}^{\text {int }}$ intrinsic equilibrium constants

$n \quad$ the number of absorbed layers

$N / N_{\mathrm{m}} \quad$ the fractions of surface coverage

$N_{\max } \quad$ the amount absorbed when $p / p_{0}$ approaches unity

$R \quad$ the molar gas constant

$S \quad$ the area of 'condensed adsorbate-vapor' equilibrium interface

S.D. the standard deviations for optimized parameters

$T$ the absolute temperature

TOTH the concentration of the total protons added to the system

$V \quad$ the pore volume

$V_{\text {at }} \quad$ the total volume of strong acid added

$V_{\mathrm{b}} \quad$ the volume of added strong base

$V_{\mathrm{eb} 1}, V_{\mathrm{eb} 2}$ two equivalence points for each suspension, the intercepts at the $V_{\mathrm{b}}$ axis in acidic and alkaline side in in situ Gran plots

$V_{\mathrm{eb} 1}^{\prime}, V_{\mathrm{eb} 2}^{\prime}$ two equivalence points for the blank system, the intercepts at the $V_{\mathrm{b}}$ axis in acidic and alkaline side in in situ Gran plots

$V_{\mathrm{L}} \quad$ molar volume of liquid absorbate

$V_{y} \quad$ the values of overall variance

$V_{0} \quad$ the initial volume of suspension

$x \quad$ the ratio of $p$ and $p_{0}$

$Z \quad$ the average number of protons reacted per surface site

$Z_{\text {net }}(\mathrm{pH}, I)$ the net number of surface reacted protons per surface site

\section{Greek letters}

$\delta \quad$ pore diameter

$\gamma \quad$ the liquid surface tension

$\Psi_{0} \quad$ the surface potential

above reactions happen on the homogenous surface of particles. However, the surface of natural particles is far from homogenization with irregular or rough morphology, non-uniform pore distribution, and the irregularity maybe similar at any magnification. Fractal models are found useful in description of natural and man-made irregular surfaces. The geometrical shape of pores and surfaces may be self-similar at different scales of magnification, which can be characterized by the surface fractal dimension [5-7]. Natural objects display the fractal behavior in the limited range of scale (pore dimensions), between so-called upper and lower cutoffs $[8,9]$. However, there is little knowledge about the fractal characteristics of natural particles within water body.

In addition, it is well known that acid-base properties of particle surface, which determine the charge of chemical groups on the particle surface, play an important role in revealing the mechanisms of above processes on the interface $[3,4]$. Moreover, some parameters about the acid-base properties of particle surface, such as surface site concentrations $\left(H_{\mathrm{s}}\right)$ and specific surface sites $\left(D_{\mathrm{OH}}\right)$, are key model parameters in the famous surface complexation models (SCMs). Wen et al. [3] simulated the heavy metal adsorption onto natural particles with three typical versions of surface complexation model: constant capacitance model (CCM), diffuse layer model (DLM), and triple layer model (TLM). Du et al. [10] and Liu et al. [11,12] also studied the surface acid-base properties of natural illites from different origins and Chinese loess with potentiometric titration and these surface complexation models, respectively. The model parameters were determined on the basis of the experimental data of the potentiometric titration and other adsorption processes. The results illustrate that SCMs can be used to successfully model natural materials.

In general, detailed analysis of the particle topography, such as surface roughness, should be considered as a part of the particle characterization because it will allow one to justify values for capacitances. For powders or amorphous absorbents, it is, at present, quite difficult to define adsorption sites in such a detailed way as would be required for the application of SCMs. Therefore, the particle surface was usually assumed to be homogenous during surface acid-base characterization and SCMs modeling, which should lead to some deviations in revealing the mechanisms of above processes on the interface. During recent years, fractal dimensions become key parameters in describing the surface roughness property of particles. It seems likely that the future developed SCMs could incorporate the fractal information of particle surface.

Now in order to provide a comprehensive knowledge of natural particle surface, a case study of the surface fractal and surface acid-base properties of natural particles around Guanting reservoir in Beijing of China was given. It will show some indications on above interface processes based on the combined aspects of physical morphology and chemical reaction.

In this paper, the pore surface fractal dimension with the corresponding fractal scale was obtained using fractal $\mathrm{FHH}$ equation and thermodynamic model. Then the potentiometric titration and surface complexation models were also employed to determine the site concentrations of hydroxyl groups in the particle surface and the corresponding acid-base reaction parameters.

\section{Materials and methods}

\subsection{Materials}

Five samples including soil particles and sediments were from some rivers and their sides around Guanting reservoir in 
Beijing of China, and their sampling points are listed as following: sample 1 from Guihe riverside soil, sample 2 from Guihe sediment, sample 3 from Yanghe entrance sediment, sample 4 from Laohuailai river sediment and sample 5 from sediment of Guanting reservoir. These samples were air-dried on flat trays, and hand-sieved to obtain the fraction with mean diameter less than $63 \mu \mathrm{m}$ [10]. The particle stack suspension was made by adding $10 \mathrm{~g}$ of sediment to $1 \mathrm{~L}$ of triple distilled water and was stored in a refrigerator at $4{ }^{\circ} \mathrm{C}$ for at least 2 weeks before the titration experiments started. The concentration of standard $\mathrm{NaOH}$ solution is $0.1368 \mathrm{~mol} \mathrm{~L}^{-1}$, and that of standard $\mathrm{HCl}$ one is $0.07088 \mathrm{~mol} \mathrm{~L}^{-1}$.

\subsection{Nitrogen adsorption-desorption isotherm}

Nitrogen adsorption measurements at $77 \mathrm{~K}$ were carried out using an automatic ASAP 2000 volumetric adsorption analyzer (Micrometrics Instrument Corp., Norcross, GA, USA). Prior to the adsorption measurements, the samples were outgassed with $\mathrm{He}$ for $16 \mathrm{~h}$ at $105^{\circ} \mathrm{C}$. The surface area and pore size distribution have been measured by above measurements. Based on the nitrogen adsorption or desorption isotherm, the surface fractal properties of particles can be determine as following fractal $\mathrm{FHH}$ isotherm equations and thermodynamic model.

To evaluate the surface fractal dimension has been performed by employing a well-established method, based on the fractal version of the Frenkel-Halsey-Hill (FHH) equations $[8,9,13]$. The classical FHH theory for multilayer adsorption was extended to the fractal surfaces in the following form:

$\ln \frac{N}{N_{\mathrm{m}}}=-\frac{1}{q} \ln (-\ln x)+C$

Here $N / N_{\mathrm{m}}$ represents the fractions of surface coverage, and $x$ is the ratio of $p$ and $p_{0}$, which are, respectively, the equilibrium and saturation pressures of the adsorbate, $C$ the intercept and the parameter $q$ is related to the surface dimension of the sample. The determination of surface fractal dimension, $D_{\mathrm{s}}$, requires knowledge of the adsorption regime. The magnitude of the parameter $1 / q$ distinguishes two possible regimes [13,14]. If the van der Waals attraction between the solid and adsorbed film, which tends to make the gas/film interface to replicate the surface roughness, is the dominant factor, the $D_{\mathrm{s}}$ value can be estimated as

$D_{\mathrm{s}}=3\left(1-\frac{1}{q}\right)$

Conversely, if the liquid/gas surface tension (capillary force), which tends to move the interface away from the surface to reduce the interface area, is more important, the $D_{\mathrm{s}}$ value can be calculated as

$D_{\mathrm{s}}=3-\frac{1}{q}$

If the desorption isotherm suggests negligible capillary condensation in the mesopore range and we should use Eq. (2) to evaluate $D_{\mathrm{s}}$. Neimark $[6,15]$ pointed out that Eq. (1) should be used with data obtained for $x>0.7$. Results of Pfeifer and Cole
[16] also indicate that Eq. (1) is valid at high $x$ values when capillary condensation is the dominate mechanism. We calculated the surface fractal dimension $D_{\mathrm{s}}$ from the slope $-(1 / q)$ of the regression given by Eq. (1) at the relative pressure $x$ in the range from 0.7320 to 0.9826 (the condensation in cryptopores occurs).

In Eq. (1) of fractal FHH isotherm equation, the exponent can be obtained from the slopes of the plot of $\ln \left[\left(N / N_{\mathrm{m}}\right)\right]$ versus $\ln \left[\ln \left(p_{0} / p\right)\right]$, and pore surface fractal dimension $D_{\mathrm{s}}$ also can be calculated by Eq. (2) or Eq. (3). Since $2 \leq D_{\mathrm{S}}<3$, Eq. (2) predicts that we should have $-1 / 3 \leq-1 / q<0$, and Eq. (3) necessitates that $-1 \leq-1 / q<0$, however, when $-1 / q \geq-1 / 3$, it appears that the value of $D_{\mathrm{s}}$ cannot be unambiguously determined from a single adsorption isotherm.

From desorption data, the surface fractal dimension $D_{\mathrm{s}}$ was estimated using the Avnir and Jaroniec equation [17]:

$\ln \frac{N}{N_{\mathrm{m}}}=\left(D_{\mathrm{s}}-3\right) \ln (-R T \ln x)+C_{1}$

where $C_{1}$ is the intercept, and the relative pressure $x$ is more than 0.53 .

The length scale, where fractal behavior was observed in above fractal FHH equation plots, was computed from the number of absorbed layers $n$ with the following equation [14]:

$n=\left(\frac{N}{N_{\mathrm{m}}}\right)^{1 /\left(3-D_{\mathrm{s}}\right)}$

Here the $N_{2}$ layer thickness is $0.35 \mathrm{~nm}$, and the length scale is the product of $n$ and $0.35 \mathrm{~nm}$. It is to be noted that the coverage, $N / N_{\mathrm{m}}$, when fractal behavior is observed in the capillary-forcecontrolled regime, is always above monolayer capacity. Thus, the calculated length scale is always larger than the $\mathrm{N}_{2}$ molecular size.

In addition to the fractal FHH theory discussed above, Neimark [6] and Neimark and Unger [15] proposed a different model based on the free energy of the liquid/gas interface, for estimating the surface fractal dimension $D_{\mathrm{s}}$ from the adsorption isotherm data. It was called the thermodynamic model, in which the same adsorption mechanism, namely, capillary condensation, is assumed, as does in fractal FHH equation. The model reflects the idea that during the adsorption on a fractal surface, the surface is smoothed by the adsorbate, and the surface of the adsorbent covered with an adsorbate is smaller than the surface of the uncovered adsorbent. The equation of the thermodynamic model:

$\ln S=\left(D_{\mathrm{s}}-2\right) \ln (-\ln x)+C_{2}$

where $S$ represents the area of 'condensed adsorbate-vapor' equilibrium interface and $C_{2}$ is the intercept. The surface fractal dimension $D_{\mathrm{s}}$ can be estimated from the slope of the regression given by Eq. (6) at relative pressure in the range from 0.7320 to 0.9826 .

The area $S$ can be calculated according to the Kiselev equation:

$S=\frac{R T}{\gamma} \int_{N\left(p / p_{0}\right)}^{N_{\max }}\left[\ln \frac{p_{0}}{p}\right] \mathrm{d} N$ 
Here $N_{\max }$ represents the amount absorbed when $p / p_{0}$ approaches unity and $\gamma$ denotes the liquid surface tension.

The area $S$ is related by the fractal law $S \propto r^{2-D_{\mathrm{s}}}$ to the mean scaling radius of the curvature of this interface $r$ which is calculated from Kelvin's equation:

$r=\frac{2 \gamma V_{\mathrm{L}}}{R T \ln x}$

where $V_{\mathrm{L}}$ molar volume of liquid absorbate. Kelvin's equation also indicates the range scale exhibiting fractal behavior.

In fact, both the theoretical and experimental results proved that the same surface fractal dimensions were obtained in the capillary condensation region by the Neimark equation and the fractal $\mathrm{FHH}$ equation with a $\left[-\left(3-D_{\mathrm{s}}\right)\right]$ exponent, but a limited range of scale in which the fractal exists, was observed in the simulation results when using Neimark's relation $[6,14,15]$.

\subsection{Potentiometric titration}

According to Dzombak and Morel's review, such factors as the nature of the sample, method of preparation of the particle suspension, method of $\mathrm{pH}$ control, equilibrium time, temperature etc., would affect the collection of data in an acid-base titration process [18]. All samples were freeze-dried and grained, then suspended to prepare the stock solution with triple distilled water. The potentiometric titration experiment was done in a 100-mL Erlenmeyer flask. A stock particle suspension was added to the flask to give a particle concentration of $5 \mathrm{~g} \mathrm{~L}^{-1}$. About $0.5 \mathrm{M} \mathrm{CaCl}_{2}$ was added to stabilize the system at a fixed ionic strength $0.005 \mathrm{~mol} \mathrm{~L}^{-1} \mathrm{CaCl}_{2}$ of the suspension. Triple distilled water was added to give a final volume of the suspension of $80 \mathrm{~mL}$. The given concentration solid solution and corresponding blank were $\mathrm{N}_{2}$ purged, then sealed and homogenized in a shaker for $5 \mathrm{~h}$ before titration. A thermostatic water-bath was used to guarantee little temperature fluctuation within $\pm 0.5^{\circ} \mathrm{C}$. For the method of $\mathrm{pH}$ control, a method of MET mode was used with same small increment titrant added, which could yield better data curve and usually used in sediment titration with a drift within $1 \mathrm{mV} / \mathrm{h}$. Other factors: the titration ends of acid side and base side were cautions selected with preexperiment.

$\mathrm{N}_{2}$ was bubbled successively through $10 \% \mathrm{NaOH}, 10 \%$ $\mathrm{H}_{2} \mathrm{SO}_{4}$, distilled water, $0.1 \mathrm{M} \mathrm{NaNO}_{3}$, and then into the suspension to exclude $\mathrm{CO}_{2}$ until the electrode potential was stable. Afterwards, $0.07088 \mathrm{~mol} \mathrm{~L}^{-1} \mathrm{HCl}$ in increments of $0.1 \mathrm{~mL}$ was gradually added to give a suspension $\mathrm{pH}$ value of less than 3 . The sample was stirred for $1 \mathrm{~h}$ with a magnetic stirrer and was equilibrated for $30 \mathrm{~min}$ to get a stable $\mathrm{pH}$. Then $0.1368 \mathrm{~mol} \mathrm{~L}^{-1}$ $\mathrm{NaOH}$ in $0.1 \mathrm{~mL}$ increments was microadded until the suspension $\mathrm{pH}$ was greater than 10; this was monitored using a Metrohm 716 automatic titroprocessor. During the titration process, the suspension was continually bubbled with $\mathrm{N}_{2}$ to exclude the effect of $\mathrm{CO}_{2}$, and the temperature was held at $25 \pm 0.5^{\circ} \mathrm{C}$. The reference blank was prepared in the same manner as the sample. The acidic suspension with $\mathrm{HCl}$ was centrifuged at $10,000 \mathrm{rpm}$ for $30 \mathrm{~min}$. The acidic suspension as system blanks were obtained and titrated, which can exclude the effect of the little fractions of impurities contained in particles. The equilibrium criterion for each addition of the titrant was that the drift in the measured potential was lower than $1 \mathrm{mV} / \mathrm{h}$

\subsection{Theory for surface acid-base reaction properties}

\subsubsection{Surface acid-base reactions}

The natural particles around Guanting reservoir can be considered to be an amphoteric surface site with surface hydroxyl groups $(\equiv \mathrm{XOH})$, which can be generally represented by the following protonation and deprotonation reactions:

$$
\begin{aligned}
& \equiv \mathrm{XOH}_{2}^{+}=\equiv \mathrm{XOH}+\mathrm{H}^{+}, \quad K_{a 1}=\frac{[\equiv \mathrm{XOH}]\left[\mathrm{H}^{+}\right]}{\left[\equiv \mathrm{XOH}_{2}^{+}\right]}, \\
& K_{a 1}^{\text {int }}=\frac{[\equiv \mathrm{XOH}]\left[\mathrm{H}^{+}\right]}{\left[\equiv \mathrm{XOH}_{2}^{+}\right]} \exp \left(\frac{F \Psi_{0}}{R T}\right)=K_{a 1} \exp \left(\frac{F \Psi_{0}}{R T}\right) \\
& \equiv \mathrm{XOH}=\equiv \mathrm{XO}^{-}+\mathrm{H}^{+}, \quad K_{a 2}=\frac{\left[\equiv \mathrm{XO}^{-}\right]\left[\mathrm{H}^{+}\right]}{[\equiv \mathrm{XOH}]} \\
& K_{a 2}^{\text {int }}=\frac{\left[\equiv \mathrm{XO}^{-}\right]\left[\mathrm{H}^{+}\right]}{\left[\equiv \mathrm{XOH}^{+}\right.} \exp \left(\frac{F \Psi_{0}}{R T}\right)=K_{a 2} \exp \left(\frac{F \Psi_{0}}{R T}\right)
\end{aligned}
$$

where $K_{a 1}, K_{a 2}$ are equilibrium constants, and $K_{a 1}^{\text {int }}, K_{a 2}^{\text {int }}$ are intrinsic equilibrium constants. $F$ is the Faraday constant $\left(\mathrm{C} \mathrm{mol}^{-1}\right), \Psi_{0}$ the surface potential $(\mathrm{V}), R$ the molar gas constant $\left(\mathrm{J} \mathrm{mol}^{-1} \mathrm{~K}^{-1}\right)$, and $T$ is the absolute temperature $(\mathrm{K})$. The values of the constants, however, are valid only for a particular ionic strength [1-4,10-12].

\subsubsection{In situ Gran plot method}

Potentiometric titration provides a measure of the sequential binding of proton by the surface function groups of these particles. In situ Gran plots [2,3,10-12] were utilized here to determine the specific volume of titrant added at the equivalence point $\left(V_{\mathrm{e}}\right)$ for the selected titration systems, as well as to obtain the total concentration of surface sites $\left(H_{\mathrm{S}}, \mathrm{mol} \mathrm{L}^{-1}\right)$ on them. For the hydroxide back titration, Gran functions are given as

- acidic side:

$$
\begin{aligned}
G & =\left(V_{0}+V_{\mathrm{at}}+V_{\mathrm{b}}\right) \times 10^{E / 59.175} \\
& =\left(V_{0}+V_{\mathrm{at}}+V_{\mathrm{b}}\right) \times 10^{-\mathrm{pH}} \times 100
\end{aligned}
$$

- alkaline side:

$$
\begin{aligned}
G & =\left(V_{0}+V_{\mathrm{at}}+V_{\mathrm{b}}\right) \times 10^{-E / 59.175} \\
& =\left(V_{0}+V_{\mathrm{at}}+V_{\mathrm{b}}\right) \times 10^{-(13.8-\mathrm{pH})} \times 100
\end{aligned}
$$

where $G$ is Gran function, $V_{0}$ the initial volume of suspension $(\mathrm{mL}), V_{\text {at }}$ the total volume of strong acid added $(\mathrm{mL}), V_{\mathrm{b}}$ the 
volume of added strong base and $E$ is the potential of the glass electrode $(\mathrm{mV})$ being a function of $\mathrm{pH}$ of suspension at each titration point.

Generally, in situ Gran plot approach, the linear regression analysis of Gran function $(G)$ versus the volume of added strong base $\left(V_{\mathrm{b}}\right)$ can determine the two equivalence points for each suspension $\left(V_{\mathrm{eb} 1}, V_{\mathrm{eb} 2}\right)$ or for the blank system $\left(V_{\mathrm{eb} 1}^{\prime}, V_{\mathrm{eb} 2}^{\prime}\right)$, which are the intercepts at the $V_{\mathrm{b}}$ axis in acidic and alkaline side.

\subsubsection{Surface acid-base reaction properties}

According to the Gran plot presented above, the added hydroxide ions successively participated in the following processes [10-12], neutralizing the excess $\mathrm{H}^{+}$(before $V_{\mathrm{eb} 1}$ ), binding to the various $\mathrm{OH}^{-}$acceptors on the particle surfaces in suspension (between $V_{\mathrm{eb} 1}$ and $V_{\mathrm{eb} 2}$ ), and contribution to the system $\mathrm{pH}$ (after $V_{\mathrm{eb} 2}$ ). Consequently, $V_{\mathrm{eb} 1}$ in Gran plots of sample suspension was regarded as the zero point of titration (ZPT), since only acid-base neutralization occurred in solution phase before this point. Therefore, for each titration point, the concentration of the total protons added to the system, denoted TOTH, was estimated by the equation

$\operatorname{TOTH}\left(\mathrm{mol} \mathrm{L}^{-1}\right)=\frac{-\left(V_{\mathrm{b}}-V_{\mathrm{eb} 1}\right) C_{\mathrm{b}}}{V_{0}+V_{\mathrm{at}}+V_{\mathrm{b}}}$

At each titration point, the amount of protons consumed by all surface sites $\left(H_{\mathrm{R}}\right)$ is computed using

$H_{\mathrm{R}}(\mathrm{mol})=\left[\mathrm{TOTH}-10^{-\mathrm{pH}}+10^{-(13.8-\mathrm{pH})}\right]\left(V_{0}+V_{\mathrm{at}}+V_{\mathrm{b}}\right)$

where $\mathrm{pH}$ and 13.8 denote the $-\log \left[\mathrm{H}^{+}\right]$and ionic product $K_{\mathrm{W}}$ of water in $0.1 \mathrm{M}$ medium, respectively.

Thus, based on the aforementioned assignment of added hydroxide ions, we further calculated the total concentration of surface sites $\left(H_{\mathrm{s}}, \mathrm{mol} \mathrm{L}^{-1}\right)$ using the acidimetric supernatant as the system blank. The formula is as follows:

$$
\begin{aligned}
& H_{\mathrm{s}}\left(\mathrm{mol} \mathrm{L}^{-1}\right) \\
& =\frac{\left[\left(V_{\mathrm{eb} 2}-V_{\mathrm{eb} 1}\right)_{\mathrm{sample}} C_{\mathrm{b}}-\left(V_{\mathrm{eb} 2}^{\prime}-V_{\mathrm{eb} 1}^{\prime}\right)_{\mathrm{blank}} C_{\mathrm{b}}\right]}{V_{0}}
\end{aligned}
$$

And the specific surface sites $\left(D_{\mathrm{OH}}\right)$ of the particles was determined by the following equation:

$D_{\mathrm{OH}}\left(\right.$ sites nm $\left.{ }^{-2}\right)=\frac{H_{\mathrm{s}} N_{\mathrm{A}}}{S C_{\mathrm{s}} \times 10^{18}}$

where $N_{\mathrm{A}}$ is constant of Avogadro, $S$ denotes the specific surface area of particles, and $C_{\mathrm{s}}$ represents the particles concentration in suspension.

At each titration point, the average number of protons reacted per surface site $(Z)$ was determined by

$Z=\frac{\left[\mathrm{TOTH}-10^{-\mathrm{pH}}+10^{-(13.8-\mathrm{pH})}\right]\left(V_{0}+V_{\mathrm{at}}+V_{\mathrm{b}}\right)}{H_{\mathrm{s}} V_{0}}$
For each particle suspension system, the net number of surface reacted protons per surface site, $Z_{\text {net }}(\mathrm{pH}, I)$, was obtained from the difference between the $Z$ values of the sample titration and the corresponding blank titration at the same $\mathrm{pH}[10]$ :

$Z_{\text {net }}(\mathrm{pH}, I)=Z_{\text {sample }}-Z_{\text {blank }}$

\subsection{Parameter estimation methods}

In this work, two frequently used surface complexation models, such as constant capacitance model (CCM) and diffuse layer model (DLM), have been used to determine the surface acidic constants of these natural particles. In general, there are two important steps when using a surface complexation model. One is to properly choose the models that relate to the assumptions of the electrical double layer and the calculation method. The other is to determine the model parameters correctly. The mass law equation and the static electronic expressions of these models can be found in the literature [19-21]. The nonlinear least squares optimization procedure with the FITEQL 4.0 program were employed to analyze the experimental data.

\section{Results and disscussion}

\subsection{Surface properties and pore surface fractal dimension of natural particles around Guanting reservior}

\subsubsection{Nitrogen adsorption-desorption isotherms}

Fig. 1 illustrates the adsorption-desorption isotherms measured on different samples of particles. The isotherms of five samples are similar to each other in shape. The adsorption branch of the isotherm of sample 5 displays some increase on reaching a relative pressure of unity. Moreover, the adsorption volume of Guanting reservoir (sample 5) is highest among these five samples, while the adsorption volume of Guihe sediment (sample 2) is lowest among them. The amounts adsorbed of other samples lie between them.

According to the Brunauer-Emmett-Teller (BET) classification, isotherms of this kind belong to the isotherms of type III describing the process of physical adsorption of nitrogen [22]. The remarkable hysteresis loops in relative pressure ranges from 0.45 to 0.99 within the isotherms implies that

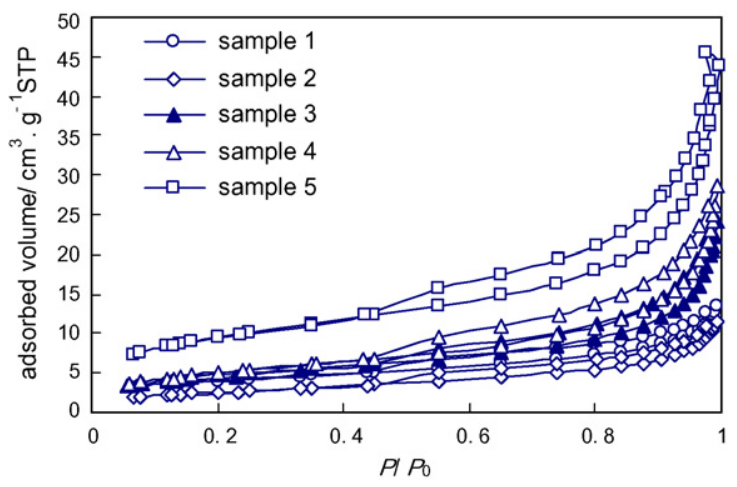

Fig. 1. Nitrogen adsorption-desorption isotherms of natural particles. 
Table 1

Specific surface areas, specific pore volumes, average pore diameters for natural particles

\begin{tabular}{|c|c|c|c|c|c|c|}
\hline Samples & $\begin{array}{l}\text { BET surface } \\
\text { area }\left(\mathrm{m}^{2} \mathrm{~g}^{-1}\right)\end{array}$ & $\begin{array}{l}\text { Micropore } \\
\text { area }\left(\mathrm{m}^{2} \mathrm{~g}^{-1}\right)\end{array}$ & $\begin{array}{l}\text { Total pore volume } \\
\left(\mathrm{cm}^{3} \mathrm{~g}^{-1}\right)\end{array}$ & $\begin{array}{l}\text { Micropore volume } \\
\left(\mathrm{cm}^{3} \mathrm{~g}^{-1}\right)\end{array}$ & $\begin{array}{l}\text { BET average pore } \\
\text { diameter }(\mathrm{nm})\end{array}$ & $\begin{array}{l}\text { BJH desorption average } \\
\text { pore diameter }(\mathrm{nm})\end{array}$ \\
\hline Sample 1 & 14.5731 & 0.01960 & 0.01872 & 0.0045 & 5.1391 & 5.6768 \\
\hline Sample 2 & 9.5669 & 0.01289 & 0.01784 & 0.00296 & 6.7463 & 6.3004 \\
\hline Sample 3 & 17.1016 & 0.02287 & 0.03441 & 0.00525 & 7.4188 & 7.2903 \\
\hline Sample 4 & 18.6144 & 0.02487 & 0.04193 & 0.00571 & 8.0092 & 7.1912 \\
\hline Sample 5 & 34.5605 & 0.004661 & 0.06656 & 0.00107 & 6.6081 & 7.7388 \\
\hline
\end{tabular}

the pores comprising the dried flocs are mostly mesoporous [23].

The adsorption and porosity properties of the samples, as calculated from the adsorption-desorption isotherms, are listed in Table 1.The specific surface areas were calculated using the BET method and were found to range from 9.5669 to $34.5605 \mathrm{~m}^{2} \mathrm{~g}^{-1}$, with the corresponding total porosity varying from 0.01784 to $0.06656 \mathrm{~cm}^{3} \mathrm{~g}^{-1}$. Sample 5 has the highest specific surface area and total pore volume among these five particles, and displays the same order in adsorbed volumes in Fig. 1. The total pore volume and the pore-size distribution were calculated using the Barrett-Joyner-Halenda (BJH) method, while the micropore volume and specific surface areas were calculated using $D-R$ equation [22]. It is clear that the micropore areas are very small in these particles, but their micropore volume of them can occupy over $15 \%$ of total pore volume.

Fig. 2 presents the pore-size-distribution as the function of $\mathrm{d} V / \mathrm{d}(\log \delta)=f(\delta)$ calculated from desorption isotherm, where $V$ is the pore volume and $\delta$ is the pore diameter. As can be seen, the pores with a diameter near $3.74 \mathrm{~nm}$ have the highest value on the curves of samples 2,3 and 4 , while a diameter near $3.25 \mathrm{~nm}$ is found on the curve of sample 1 , and a diameter near $5.17 \mathrm{~nm}$ on the curve of sample 5. Table 1 also shows the $\mathrm{BJH}$ average pore diameters of samples 3 and 4 have near average pore diameters close to $7.20 \mathrm{~nm}$, while sample 5 has ones close to $7.74 \mathrm{~nm}$. Additionally, sample 2 has a large BJH average pore diameter than sample 1 .

\subsubsection{Pore surface fractal dimension calculation of particles around Guanting reservior}

Both the $\ln \left[\left(N / N_{\mathrm{m}}\right)\right]$ versus $\ln \left[\ln \left(p_{0} / p\right)\right]$ plots and the $\ln S$ versus $\ln \left[\ln \left(p_{0} / p\right)\right]$ ones for different samples are given in Fig. 3,

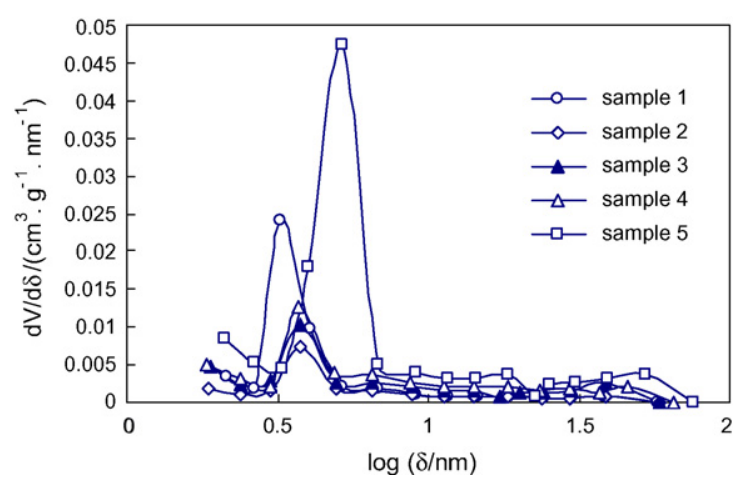

Fig. 2. Pore size distribution curves of natural particles. the linear regression equations and the values of the correlation coefficient are listed in the figure captions, and the surface fractal dimension calculated with Eq. (1), Eq. (3), Eq. (4) or Eq. (6) are collected in Table 2. Also given is the length scale where fractal characteristic was observed. The linear behavior of above plots between the ranges of $p / p_{0}$ was employed to prove the surface fractal characteristic of samples.

According to Table 2, when using fractal FHH isotherm equation to fit the data of adsorption branch in the isotherm, the slopes $-1 / q$ of linear range for all samples are higher than $-1 / 3$. Under these conditions, it has been proposed that the desorption isotherm should also be measured to ensure the presence of capillary condensation within mesopores [16]. Fig. 1 shows existence of the remarkable hysteresis loops and capillary condensation effect within mesopores, and indicates that the liquid/gas surface tension (capillary force) is dominant, therefore, the $D_{\mathrm{s}}$ value can be calculated according to Eq. (3). The calculated surface fractal dimensions $\left(D_{\mathrm{s}}\right)$ are between 2.69 and 2.7955 , and sample 1 shows the highest $D_{\mathrm{s}}$ value. The corresponding fractal scales, i.e. the length scales for linear behavior are among $0.038-56.21 \mathrm{~nm}$. When using the Avnir and Jaroniec equation (Eq. (4)) with the data from the desorption branch in the isotherms, the $D_{\mathrm{s}}$ values for all samples are higher than above ones with the adsorption data, and the corresponding fractal scales are among $0.034-73.76 \mathrm{~nm}$. It is strange that when computing $D_{\mathrm{s}}$ values by thermodynamic model (Eq. (6)), all the obtained $D_{\mathrm{s}}$ values are very close or more than 3 , the maximum value of surface fractal dimension, while the linear length scale is observed for some samples.

The obtained $D_{\mathrm{s}}$ values for these particles imply a wiggly and space-filling surface $[14,23]$. The minimum limits of fractal scales for samples 1 and 2 are very less than $0.2 \mathrm{~nm}$, the radius of nitrogen. According to fractal FHH equation principal, the $D_{\mathrm{s}}$ values are obtained through surface coverage by nitrogen, so the minimum covering scale is as long as the radius of nitrogen. That is to say, the calculated $D_{\mathrm{s}}$ values can describe a wiggly surface within scales at least longer than $0.2 \mathrm{~nm}$. Then the minimum limits of fractal scales for $D_{\mathrm{s}}$ values of samples 1 and 2 obtained by fractal FHH equation should be no less than $0.2 \mathrm{~nm}$. Furthermore, the fractal scales for the former samples are among $0.2-12.30 \mathrm{~nm}$, while that for sample 5 is among 2.68-73.36, much wider than them. Although the maximum limits of fractal scales for sample 5 are higher than $50 \mathrm{~nm}$, exceeding to mesoporous scale, they are still in pore size scales of particles. 

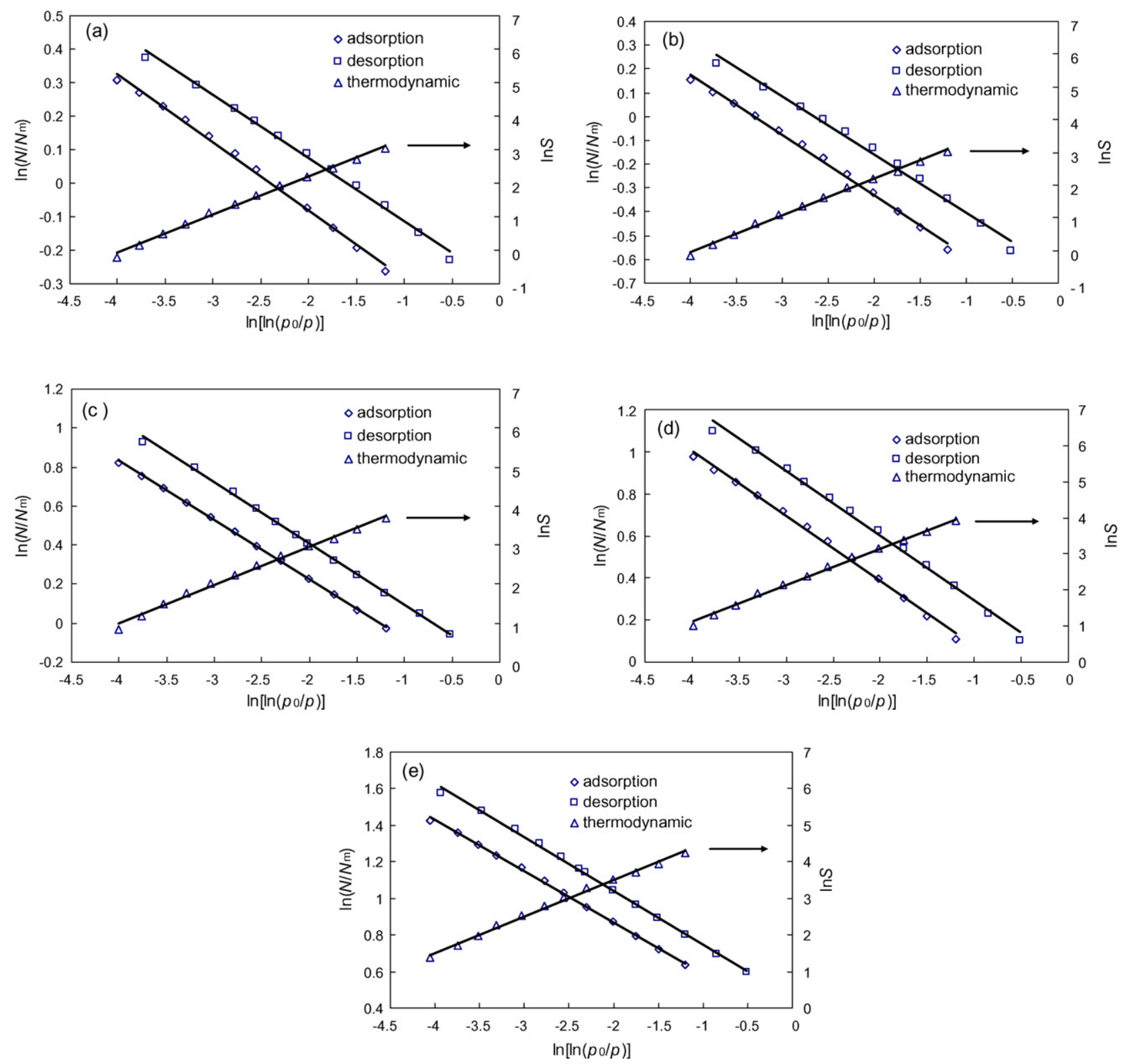

Fig. 3. Fractal analysis according to fractal FHH isotherm equation and thermodynamic model (a: sample 1, b: sample 2, c: sample 3, d: sample 4, e: sample 5). (a) Adsorption: $y=-0.2045 x-0.4914, R^{2}=0.9968$; desorption: $y=-0.1874 x-0.2996, R^{2}=0.9944$; thermodynamic: $y=1.1357 x+4.4674, R^{2}=0.996$. (b) Adsorption: $y=-0.2541 x-0.8395, R^{2}=0.9959$; desorption: $y=-0.2442 x-0.6468, R^{2}=0.9911$; thermodynamic: $y=1.1223 x+4.4331, R^{2}=0.9958$. (c) Adsorption: $y=-0.3046 x-0.3866, R^{2}=0.9996$; desorption: $y=-0.3127 x-0.218, R^{2}=0.9986$; thermodynamic: $y=0.9854 x+4.9323, R^{2}=0.9936$. (d) Adsorption: $y=-0.31 x-0.2363, R^{2}=0.9969$; desorption: $y=-0.3088 x-0.0169, R^{2}=0.9943$; thermodynamic: $y=1.0186 x+5.1876, R^{2}=0.996$. (e) Adsorption: $y=-0.2811 x-0.3044, R^{2}=0.999$; desorption: $y=-0.2945 x-0.4523, R^{2}=0.9978$; thermodynamic: $y=0.9962 x+5.5028, R^{2}=0.9955$.

Table 2

Pore surface fractal dimensions of natural particles around Guanting reservoir

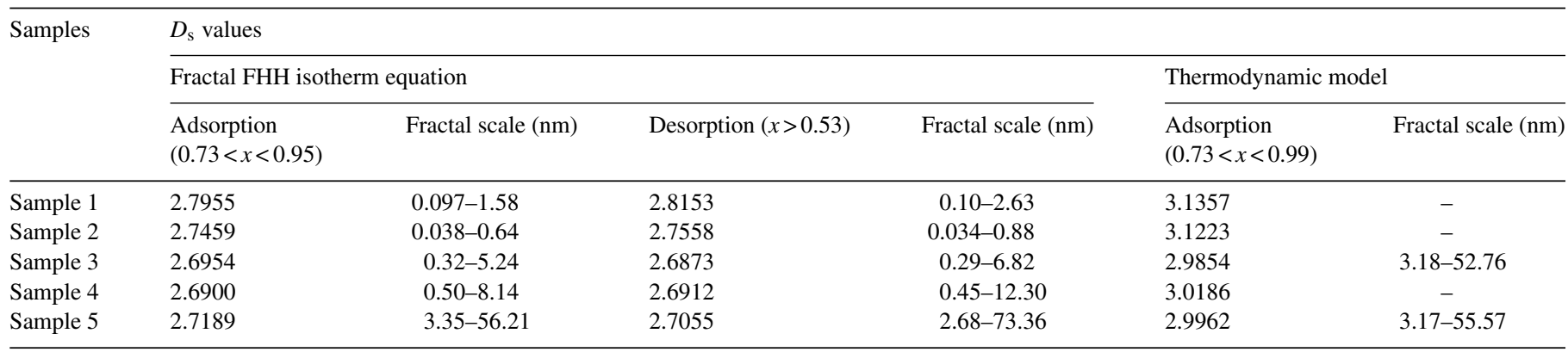


The geometrical irregularities and roughness of the surface are the essential reasons for the obtained $D_{\mathrm{s}}$ values, but it is known that absorbed film volume and pore size distribution are used to define fractal in fractal FHH equation $[14,15]$. Then the FHH type equation might be sensitive to the pore size distribution, and therefore, pore size distribution can contribute significantly to the surface fractal dimension [14]. While the thermodynamic model proposed by Neimark introduces the fractal definition of surface area of absorbed film $[6,14,15]$. Lee and Tsay [24] indicate that rough surfaces may be divided into two general categories: roughness due to the presence of uniform pores, and roughness due to the presence of a distribution of pore sizes. Gamal M.S. El Shafei et al. [14] show that the non-uniform pore system, containing pores of different radii with different frequencies, often causes disagreement between the values of $D_{\mathrm{s}}$ obtained from fractal FHH equation and thermodynamic model, and the pore size uniformity of sample could be proved through a distribution of pore size with asymptotically increasing on reaching a relative pressure of unity in the adsorption branch of the isotherm [14]. However, Fig. 1 shows that above asymptotically increasing is not existed in the adsorption branch of the isotherm when a relative pressure reached unity. The obtained $D_{\mathrm{s}}$ values are far different with these two equations as shown in Table 2. For samples 3 and 5, both the $D_{\mathrm{s}}$ values and corresponding fractal scales can be determined by thermodynamic model, however, the $D_{\mathrm{s}}$ values are very close to 3 , meaning that the pore surface of samples 3 and 5 has the highest filling-space. These phenomena may be an unusual description for the pore surface of particles.

In addition, the obtained $D_{\mathrm{s}}$ values, when using the data of the adsorption branch of the isotherm, show a little difference from ones with the isotherm data of desorption branch. It may be attributed to the different $p / p_{0}$ range for $D_{\mathrm{s}}$ values calculation and pore structure property.

\subsection{Surface acid-base properties}

\subsubsection{In situ Gran plots}

Fig. 4 gives the plots of the $\mathrm{pH}$ of suspension versus the volume of added strong base $\left(V_{\mathrm{b}}\right)$ for $5 \mathrm{~g} \mathrm{~L}^{-1}$ suspension and the corresponding acidic blank system in $0.005 \mathrm{~mol} \mathrm{~L}^{-1} \mathrm{CaCl}_{2}$ by

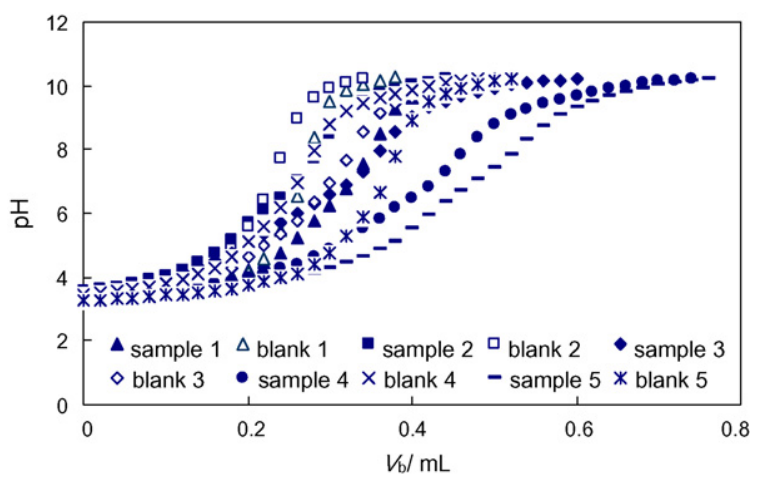

Fig. 4. Titration curves of the sample and its blank system. potentiometric titration method. As Fig. 4 shown, a less difference was found for sample 3 (Yanghe entrance sediment) between the hydroxide titration curves of the suspension and its blank system than other samples. Moreover, during the hydroxide titration, the added $\mathrm{NaOH}$ first reacted with the excess $\mathrm{HCl}$ added from the acid titration. After that, the added $\mathrm{OH}^{-}$began to react with the solid surface and the remainder contributed to the $\mathrm{pH}$ value of the system [10-12].

Fig. 5 shows the Gran plots of $5 \mathrm{~g} \mathrm{~L}^{-1}$ suspensions and the corresponding acidic blank systems in $0.005 \mathrm{~mol} \mathrm{~L}^{-1} \mathrm{CaCl}_{2}$, and the obtained values of equivalence points with corresponding $\mathrm{pH}$ values for each suspension and its blank systems are list in Fig. 5.

\subsubsection{Surface acid-base reaction properties of the samples}

The results of $H_{\mathrm{s}}$ and $D_{\mathrm{OH}}$ are summarized in Table 3.It is clearly that there are about $1-2$ sites in each square nanometers on these particles surface, which proves that the concentration of surface hydroxyl groups is also 1-2 sites on the same area.

At each titration point, the average number of protons reacted per surface site $(Z)$ in Fig. 6 was determined by Eq. (17).

In Fig. 6, the Z-plots for the five suspensions indicate that the number of net surface reacted protons per surface site $(Z)$ increase with $\mathrm{pH}$ decrease. At most $\mathrm{pH}$ range, $Z$ have negative values, and only when $\mathrm{pH}$ values are lower than about $4, Z$ can have positive values.

Furthermore, the potentiometric titration data sets, in the format of total concentration of reacted proton (TOTH) versus $\mathrm{pH}$, are input into the FITEQL program, Version 4.0, with a nonlinear least-squares optimization procedure for analysis of the intrinsic equilibrium constants $\left(K_{a 1}^{\mathrm{int}}, K_{a 2}^{\mathrm{int}}\right)$.

Theoretically, only one plane in the intersurface region is considered in CCM. All the specific adsorbed ions are assigned as inner-sphere complex by the surface coordination reactions in this model, and they contribute to surface charge $\sigma_{0}$ and experience the potential $\psi_{0}$. The electrical double layers are Helmholtz type, like a parallel plate capacitor with a fixed electrical capacitance $(C)$ for each of the corresponding combinations of temperature, ionic strength, and the electrolyte property $[2,3,10-12,25]$. In this model calculations, four specific parameters $\left(C, K_{a 1}^{\mathrm{int}}, K_{a 2}^{\mathrm{int}}\right.$ and $\left.H_{\mathrm{s}}\right)$ are arranged as adjustable ones. Then, by changing theses parameters, the best fit is achieved at most. In this study, the CCM simulation for samples 2, 3 and 4 achieved the optimization procedure converged, but for samples 1 and 5 did not achieve. For these two samples, two surface intrinsic equilibrium constants were selected from the no convergence simulation results but with best fit with the TOTH versus $\mathrm{pH}$ experiment data and fixed as optimized ones, and input them into FITEQL 4.0 program for $H_{\mathrm{s}}$ optimization. After that, the surface intrinsic equilibrium constants and the optimized total concentration of surface sites for these natural particles in specific electrolyte concentration are list in Table 3. As we can see, the $H_{\mathrm{s}}$ values estimated and optimized are of the same order of magnitude, the values of overall variance $\left(V_{\mathrm{y}}\right)$, which are the indicators of goodness of the fit, are between 8.0 and 17.5, 

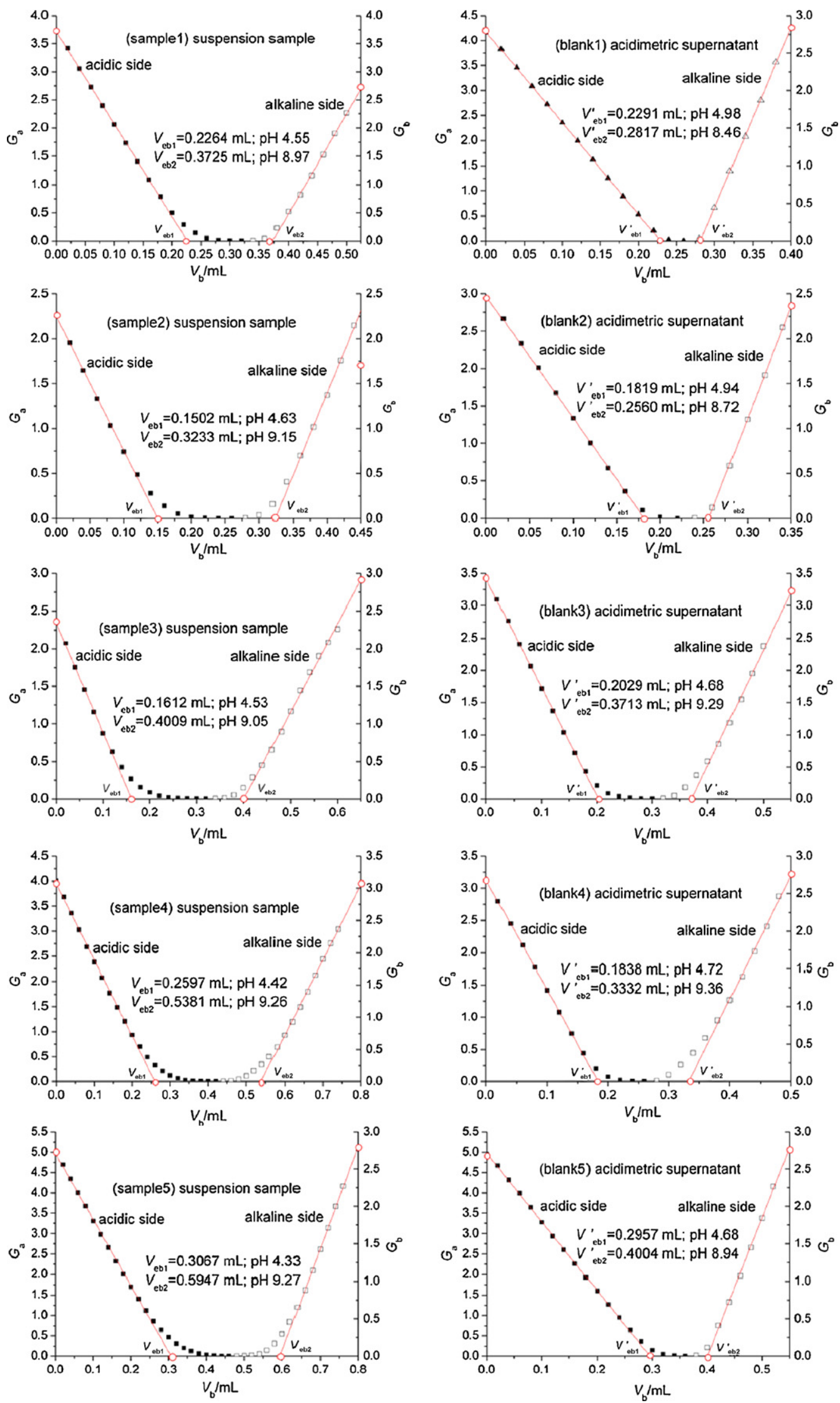

Fig. 5. In situ Gran plots of the sample and its blank system. Acidic side represents acidic side in alkalimetric back titration, alkaline side represents alkaline side in alkalimetric back titration. 


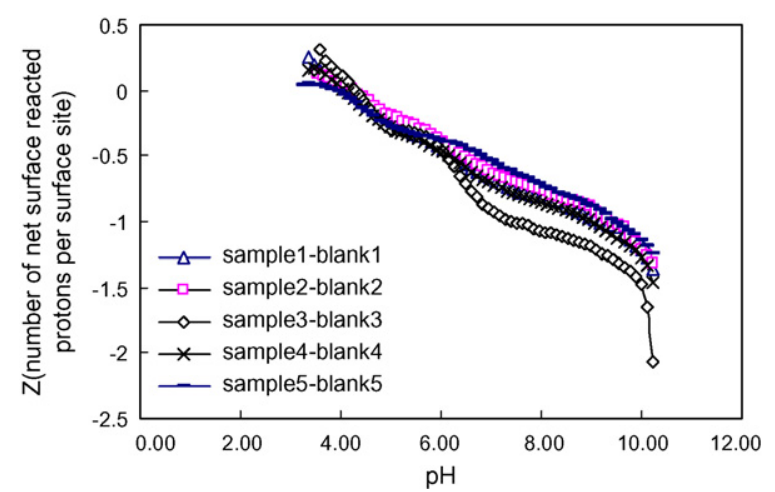

Fig. 6. pH-dependent net number of surface-reacted protons per surface site.

and the standard deviations (S.D.) for optimized parameters are within 0.5847 . These results indicate that the protonation and deprotonation reactions model can successfully depicted the acid-base behavior of natural particles surface. In turn, the derived parameters are incorporated into the model to reproduce the titration curves as depicted in Fig. 7. It is obvious that the natural particle samples are negatively charged over a large $\mathrm{pH}$ range, and model calculation results match well with the experimental results.

In DLM, two planes in the intersurface region is considered: a surface plane for adsorption of $\mathrm{H}^{+}, \mathrm{OH}^{-}$, and all specifically adsorbed species, and a diffuse layer plane representing the closest distance of approach for all counterions. The Poisson-Boltzmann equation is employed to describe the distribution of ions, charge, and potential in the diffuse layer. The overall relationship between surface charge and the potential is given by the Gouy-Chapman equation [3]. As indicated by Dzombak and Morel [18], DLM uses only two constants $\left(p K_{a 1}^{\mathrm{int}}, p K_{a 2}^{\mathrm{int}}\right)$ to express the surface characteristics at variable ionic strengths. In this work, three specific parameters $\left(K_{a 1}^{\text {int }}\right.$, $K_{a 2}^{\text {int }}$ and $\left.H_{\mathrm{s}}\right)$ are arranged as adjustable ones [2,3,10-12]. Then, like CCM, by changing these parameters, the DLM simulation for samples 2 and 3 achieved the optimization procedure converged, but for samples 1, 4 and 5 did not achieve. For these three samples, two surface intrinsic equilibrium constants were selected from the no convergence simulation results but with best fit with the TOTH versus $\mathrm{pH}$ experiment data and fixed as optimized ones, and input them into FITEQL 4.0 program for $H_{\mathrm{s}}$ optimization. After that, the surface intrinsic equilibrium constants and the optimized total concentration of surface sites for these natural particles at $0.005 \mathrm{~mol} \mathrm{~L}^{-1}$ electrolyte concentration are list in Table 3. As shown in Table 3, the $H_{\mathrm{s}}$ values estimated and optimized are of the same order of magnitude, the values of overall variance $\left(V_{\mathrm{y}}\right)$, which are the indicators of goodness of the fit, are between 10.6 and 80.3, and the standard deviations (S.D.) for optimized parameters are within 0.2842 . These results indicate that the DLM simulation can achieve better fit for samples 1, 2 and 3 than that for samples 4 and 5. Moreover, the derived parameters are used in the model to reproduce the titration curves for these five samples as depicted in Fig. 7. It can be seen that the natural particle samples are negatively charged over a large $\mathrm{pH}$ range, and model calculation results only match much part of the experimental data points.

Additionally, comparing the simulation results using CCM and DLM, it can be given that the former can better interpret the experiment data points than the latter at $0.005 \mathrm{~mol} \mathrm{~L}^{-1}$ ion strength, which means that the surface complexation modelCCM can apply very well in describing the acid-base behavior of the natural particles.

Table 3

Surface-acid base characteristic parameters of the particles at a fixed ionic strength 0.001 of the suspension

\begin{tabular}{|c|c|c|c|c|c|}
\hline Parameters & Samples 1 & Sample 2 & Sample 3 & Sample 4 & Sample 5 \\
\hline Estimated $H_{\mathrm{S}}\left(\mathrm{mmol} \mathrm{L}^{-1}\right)$ & 0.1599 & 0.1692 & 0.1219 & 0.2207 & 0.3134 \\
\hline Estimated $D_{\mathrm{OH}}\left(\right.$ sites nm $\left.{ }^{-2}\right)$ & 1.3211 & 2.1305 & 0.8586 & 1.4282 & 1.0923 \\
\hline \multicolumn{6}{|l|}{ CCM model } \\
\hline$C\left(\mathrm{~F} / \mathrm{m}^{2}\right)$ & 2.400 & 3.800 & 3.800 & 1.800 & 1.200 \\
\hline$p K_{a 1}^{\text {int }}$ & 2.000 & 1.53094 & 1.75269 & 2.70085 & 2.000 \\
\hline$p K_{a 2}^{\text {int }}$ & 5.132 & 5.21763 & 5.38606 & 4.71637 & 4.815 \\
\hline Optimized $H_{\mathrm{s}}\left(\mathrm{mmol} \mathrm{L}^{-1}\right)$ & 0.2243 & 0.2622 & 0.3792 & 0.5237 & 0.4733 \\
\hline$V_{\mathrm{y}}$ & 17.44089 & 8.09644 & 8.72043 & 11.57568 & 13.04500 \\
\hline S.D. $H_{\mathrm{s}}$ & $1.605 \times 10^{-6}$ & $2.008 \times 10^{-6}$ & $1.873 \times 10^{-6}$ & $9.126 \times 10^{-6}$ & $2.816 \times 10^{-6}$ \\
\hline S.D. $\left(p k_{a 1}^{\text {int }}\right)$ & - & $5.847 \times 10^{-1}$ & $2.432 \times 10^{-1}$ & $5.826 \times 10^{-2}$ & - \\
\hline S.D. $\left(p k_{a 2}^{\text {int }}\right)$ & - & $1.548 \times 10^{-2}$ & $1.021 \times 10^{-2}$ & $2.388 \times 10^{-2}$ & - \\
\hline \multicolumn{6}{|l|}{ DLM model } \\
\hline$C\left(\mathrm{~F} / \mathrm{m}^{2}\right)$ & - & - & - & - & - \\
\hline$p K_{a 1}^{\mathrm{int}}$ & 1.500 & 1.53857 & 1.69690 & 2.000 & 2.000 \\
\hline$p K_{a 2}^{\text {int }}$ & 4.570 & 4.40904 & 4.53927 & 4.546 & 4.657 \\
\hline Optimized $H_{\mathrm{S}}\left(\mathrm{mmol} \mathrm{L}^{-1}\right)$ & 0.2169 & 0.2464 & 0.3617 & 0.3920 & 0.3951 \\
\hline$V_{\mathrm{y}}$ & 20.37703 & 10.63752 & 26.34678 & 59.39350 & 80.33724 \\
\hline S.D. $H_{\mathrm{S}}$ & $1.350 \times 10^{-6}$ & $1.562 \times 10^{-6}$ & $1.632 \times 10^{-6}$ & $1.426 \times 10^{-6}$ & $1.457 \times 10^{-6}$ \\
\hline S.D. $\left(p k_{a 1}^{\text {int }}\right)$ & - & $2.842 \times 10^{-1}$ & $1.681 \times 10^{-1}$ & - & - \\
\hline S.D. $\left(p k_{a 2}^{\text {int }}\right)$ & - & $1.556 \times 10^{-2}$ & $1.111 \times 10^{-1}$ & - & - \\
\hline
\end{tabular}



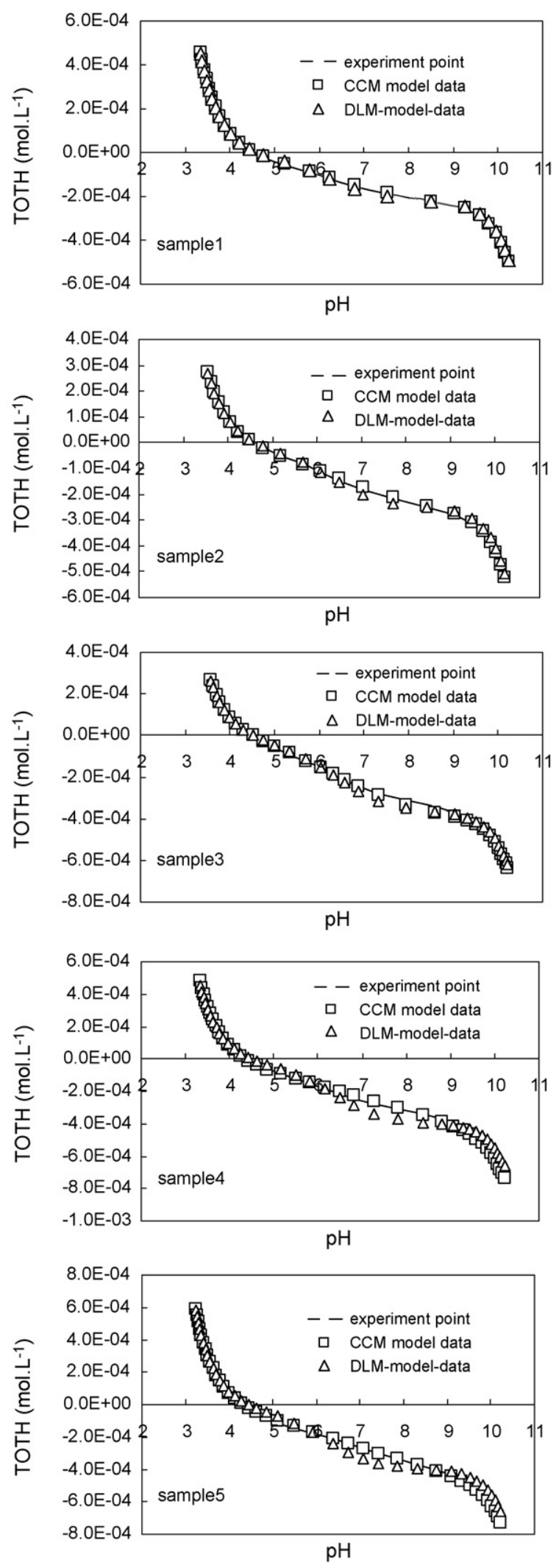

Fig. 7. Model description and actual titration data of five samples.

\section{Conclusion}

The nitrogen absorption-desorption data determined the microstructure of the natural particles around Guanting reservior: $9.5669-4.5605 \mathrm{~m}^{2} \mathrm{~g}^{-1}$ of BET specific surface area, $0.01784-0.06656 \mathrm{~cm}^{3} \mathrm{~g}^{-1}$ of BJH cumulative absorbed volume and $7.20-7.74 \mathrm{~nm}$ of $\mathrm{BJH}$ desorption average pore diameter. The peak values of pore size distribution (PSD) curves were found at near $3.74 \mathrm{~nm}$ for samples 2, 3 and 4, and near $3.25 \mathrm{~nm}$ for sample 1, and near $5.17 \mathrm{~nm}$ for sample 5. The micropore areas are very small in these particles, but their micropore volume of them can occupy over $15 \%$ of total pore volume.

Both fractal FHH equation and thermodynamic model with nitrogen absorption-desorption data gives the pore surface fractal dimensions $D_{\mathrm{s}}$ and its corresponding fractal scale of the natural particles around Guanting reservoir. The obtained $D_{\mathrm{s}}$ values with fractal FHH equation, when using the data of the adsorption branch of the isotherm, are less than ones with the isotherm data of desorption branch, and also the former corresponding fractal scales are narrower than the latter. Otherwise, the computing $D_{\mathrm{s}}$ values by thermodynamic model do not give meaningful indication for particle surface irregularity.

Potentiometric titration experiment and two surface complexation model simulation results indicate that CCM simulation results can better interpret the experiment data points than DLM at $0.005 \mathrm{~mol} \mathrm{~L}^{-1}$ ion strength, and base on the CCM, the protonation and deprotonation reactions model can successfully depicted the acid-base behavior of natural particles surface. The parameters optimized with FITEQL programe 4.0, such as surface intrinsic acidic constants and the total concentration of surface sites for these natural particles, are obtained (see Table 3$)$. The calculated specific surface sites $\left(D_{\mathrm{OH}}\right)$ show that there are about 1-2 sites in each square nanometers on these particles surface, and the Z-plots indicate that at most $\mathrm{pH}$ range, $Z$ have negative values, and only when $\mathrm{pH}$ values are lower than about $4, Z$ can have positive values.

\section{Acknowledgements}

The receipt of a research grant under the programme funded by National Natural Science Foundation of PR China (No. 20407004, No. 50578012, No. 50178009), Fok-YingTung Education Fundation of National Education Ministry (No. 91078), Beijing Municipal Commission of Education Project, Program for New Century Excellent Talents in University (NCET), Beijing Nova of Science and technology, Beijing key subject (No. XK100220555) and BFU Post Graduate Foundation (No. 05jj006).

\section{References}

[1] H.X. Tang, Aspects of chemistry in environmental sciences: some chemical hotspots in environmental water quality sciences, Prog. Chem. 12 (2000) 415-422 (in Chinese).

[2] R.X. Liu, X.M. Liu, H.X. Tang, Y.B. Su, Sorption behavior of dye compounds onto natural sediment of Qinghe river, J. Colloid Interface Sci. 239 (2001) 475-482. 
[3] X.H. Wen, Q. Du, H.X. Tang, Surface complexation model for the heavy metal adsorption on natural sediment, Environ. Sci. Technol. 32 (1998) 870-875.

[4] W. Stumm, Chemistry of the Solid-water Interface: Process at the Mineral-water and particle-water Interface in Natural System, Wiley, New York, 1992.

[5] D. Avnir, D. Farin, P. Pfeifer, Surface geometric irregularity of particulate materials: the fractal approach, J. Colloid Interface Sci. 103 (1985) $112-123$.

[6] A.V. Neimark, Determination of surface fractal dimension from the results of an adsorption experiment, Russ. J. Phys. Chem. 64 (1990) 1398-1403.

[7] P. Pfeifer, M. Obert, Fractals: basic concepts and terminology, in: D. Avnir (Ed.), The Fractal Approach to Heterogeneous Chemistry, Wiley, New York, 1989.

[8] M. Hajnos, L. Korsunskaia, Y. Pachepsky, Soil pore surface properties in managed grasslands, Soil Tillage Res. 55 (2000) 63-70.

[9] G. Jozefaciuk, A. Muranyi, A. Szatanik-Kloc, C. Farkas, C. Gyuricza, Changes of surface, fine pore and variable charge properties of a brown forest soil under various tillage practices, Soil Tillage Res. 59 (2001) 127-135.

[10] Q. Du, Z.X. Sun, W. Forsling, H.X. Tang, Acid-base properties of aqueous illite surfaces, J. Colloid Interface Sci. 187 (1997) 221-231.

[11] W.X. Liu, Z.X. Sun, W. Forsling, Q. Du, H.X. Tang, A comparative study of acid-base characteristics of natural illites from different origins, J. Colloid Interface Sci. 219 (1999) 48-61.

[12] W.X. Liu, Z.S. Chu, H.X. Tang, T.W. Qian, S.S. Li, Z.T. Li, G.B. Wu, Study on surface acid-base properties of Chinese loess, Acta Scientiae Circumstantiae 23 (2003) 6-10 (in Chinese).

[13] Z. Sokołowska, S. Sokołowski, Influence of humic acid on surface fractal dimension of kaolin: analysis of mercury porosimetry water vapour adsorption data, Geoderma 88 (1999) 233-249.
[14] M.S. El Shafei Gamal, A. Philip Christine, A. Moussa Nabawaya, Fractal analysis of hydroxyapatite from nitrogen isotherms, J. Colloid Interface Sci. 277 (2004) 410-416

[15] A.V. Neimark, K.K. Unger, Method of discrimination of surface fractality, J. Colloid Interface Sci. 158 (1993) 412-419.

[16] P. Pfeifer, M.W. Cole, Fractals in surface science: scattering and thermodynamics of adsorbed film-II, New J. Chem. 14 (1990) 221-232.

[17] M. Jaroniec, M. Kruk, Fractal analysis of composite adsorption isotherms by using density functional theory data for argon in slitlike pores, Langmuir 13 (1997) 1031-1035.

[18] D.A. vcDzombak, F.M.M. Morel, Surface Complexation Modeling: Hydrous Ferric Oxide, John Wiley, New York, 1990.

[19] W. Stumm, C.P. Huang, S.R. Jenkins, Specific chemical interaction affecting the stability of dispersed systems, Croat. Chem. Acta 42 (1970) 223-244.

[20] H. Hohl, W. Stumm, Interaction of $\mathrm{Pb}^{2+}$ with hydrous $\gamma-\mathrm{A1}_{2} \mathrm{O}_{3}$, J. Colloid Interface Sci. 55 (1976) 281-288.

[21] C.P. Huang, H.A. Elloitt, R.M. Ashmead, Interfacial reactions and the fate of heavy metals in soil-water systems, J. Water Pollut. Control Fed. 49 (1977) 745-756.

[22] Z.G. Zhao, Application Principals of Adsorption, Chemical Industry Press, Beijing, 2005 (in Chinese).

[23] S. Pyuna, C.K. Rheeb, An investigation of fractal characteristics of mesoporous carbon electrodes with various pore structures, Electrochim. Acta 49 (2004) 4171-4180.

[24] C.K. Lee, C.S. Tsay, Surface fractal dimension of alumina and aluminum barate from nitrogen isotherms, J. Phys. Chem. B 102 (1998) 41234130.

[25] J.A. Davis, D.B. Kent, in: M.F. Hochella Jr, A.F. White (Eds.), Mineral-water Interface Geochemistry, Mineralogical Society of America, Madison, WI, 1990, pp. 177-259. 